\title{
Sulodexide therapy for the treatment of diabetic nephropathy, a meta-analysis and literature review
}

This article was published in the following Dove Press journal:

Drug Design, Development and Therapy

3 December 2015

Number of times this article has been viewed

\section{Rui $\mathrm{Li}^{\prime}$ \\ Jing Xing' \\ Xaojing $\mathrm{Mu}^{2}$ \\ Hui Wang ${ }^{\prime}$ \\ Lei Zhang ${ }^{3}$ \\ Yu Zhao' \\ Yu Zhang'}

'Emergency Department, First Affiliated Hospital of Dalian Medical University, ${ }^{2}$ Dalian Hospital of

Traditional Chinese Medicine, Dalian, People's Republic of China; Intensive Care Unit, Tianjin First Central Hospital, People's Republic of China
Correspondence: Yu Zhang Emergency Department, First Affiliated Hospital of Dalian Medical University, Number 222, ZhongShan, Dalian II60 II, People's Republic of China Tel +86 4II 83635963 Email yuzhangmd@yeah.net
Abstract: Sulodexide is a heterogeneous group of sulfated glycosaminoglycans (GAGs) that is mainly composed of low-molecular-weight heparin. Clinical studies have demonstrated that sulodexide is capable of reducing urinary albumin excretion rates in patients with type 1 and type 2 diabetes, suggesting that sulodexide has renal protection. However, this efficacy remains inconclusive. In this article, we used meta-analysis to summarize the clinical results of all prospective clinical studies in order to determine the clinical efficacy and safety of sulodexide in diabetic patients with nephropathy. Overall, sulodexide therapy was associated with a significant reduction in urinary protein excretion. In the sulodexide group, $220(17.7 \%)$ achieved at least a 50\% decrease in albumin excretion rate compared with only $141(11.5 \%)$ in the placebo. The odds ratio comparing proportions of patients with therapeutic success between the sulodexide and placebo groups was 3.28 ( $95 \%$ confidence interval, $1.34-8.06 ; P=0.01$ ). These data suggest a renoprotective benefit of sulodexide in patients with diabetes and micro- and macroalbuminuria, which will provide important information for clinical use of this drug as a potential modality for diabetic nephropathy, specifically, the prevention of end-stage renal disease that is often caused by diabetes.

Keywords: sulodexide, diabetic nephropathy, meta-analysis, odds ratio

\section{Introduction}

The increased prevalence of diabetes has also led to an increase in the number of macro- and microvascular complications of diabetes, such as coronary heart disease, stroke, visual impairment, diabetic kidney disease, and end-stage renal disease. Diabetic nephropathy (DN) is a multifactorial complication with long-term consequences of chronic renal insufficiency. ${ }^{1}$ It is one of the major causes of end-stage renal disease and is associated with increased cardiovascular morbidity and mortality. ${ }^{2}$ Diabetic kidney disease was previously known as DN and is defined as diabetes with albuminuria (ratio of urine albumin to creatinine $\geq 30 \mathrm{mg} / \mathrm{g}$ ), impaired glomerular filtration rate $\left(<60 \mathrm{~mL} / \mathrm{min} / 1.73 \mathrm{~m}^{2}\right)$, or both, and is the single strongest predictor of mortality in patients with diabetes. ${ }^{3}$ However, diabetic kidney disease encompasses not only DN but also atheroembolic disease, ischemic nephropathy, and interstitial fibrosis that occurs as a direct result of diabetes. ${ }^{4}$ Therefore, early identification of intensive therapy for DN is urgently needed. In addition to oxidative stress and hemodynamic changes, glycosaminoglycans (GAGs) are another factor contributing to the onset of glomerular abnormalities in diabetic patients. ${ }^{1}$ The thickening of glomerular basement membrane (GBM) and the depletion of GAGs cause decreased electrostatic charge barrier in the pathophysiology of DN. ${ }^{5}$ A novel therapeutic approach for DN is the reestablishment of heparin sulfate synthesis by GAG drugs. ${ }^{6}$ GAG replacement therapy for DN began 20 years ago, and sulodexide is the most extensively studied of the GAGs used to reduce albuminuria in diabetic patients. ${ }^{7,8}$ Sulodexide is composed of low-molecular-weight 
heparin and dermatan sulphate. ${ }^{9}$ Glycosaminoglycan sulodexide may affect the morphology and function of the basement membranes in microvessels. Sulodexide may protect against DN initiation and progression, as manifested by the reduced albuminuria. ${ }^{10}$ However, two collaborative trials have adequately assessed the efficacy of sulodexide in patients with type 2 diabetes mellitus (DM) and failed to demonstrate renoprotection for both micro-(incipient) and macro-(overt) albuminuria. ${ }^{11,12}$ Therefore, we performed this meta-analysis to investigate the effect of sulodexide on the progression of proteinuria in DN patients.

\section{Material and methods}

\section{Search strategy}

We searched PubMed, MEDLINE, and Web of Science, Scopus, and EMBASE in April 2015, using the following search terms: "diabetic nephropathy", "proteinuria", "albuminuria", and "sulodexide". We screened the publications by titles first, then the abstracts. We then evaluated the full-text version for inclusion and exclusion criteria, after exclusion of nonrelevant publications and identifications of duplicates from the different databases. The languages of publication was were restricted to English and Chinese. All clinical studies except case reports were chosen. All searched data were retrieved. Authors' bibliographies and references of selected studies were also searched for other relevant studies.

\section{Selection criteria}

In this meta-analysis, we collected all eligible articles about relationship between sulodexide and micro-/macroalbuminuria and clinical outcomes in DN. The following inclusion criteria were applied: (1) type of study design was a randomized controlled trial that compared sulodexide with placebo, no treatment, or other antihypertensive drugs (excluding angiotensin-converting enzyme inhibitors [ACEIs] and angiotensin receptor blockers [ARBs]) on the effect of urinary albumin excretion; (2) all the participants were diabetic patients with proteinuria; (3) the study reported the changes in urinary protein excretion from baseline; and (4) study duration was longer than 3 weeks. The following exclusion criteria were applied: (1) articles that had no information on proteinuria or that could not be calculated by the albumin excretion ratio of means from the given information; (2) case reports, letters, reviews, expert opinion, conference abstracts, editorials, and non-English- and non-Chineselanguage papers; and (3) all articles using cell lines, human xenografts, and in vitro/ex vivo studies.

\section{Data extraction}

The eligible studies were extracted by two investigators independently. Disagreements were resolved by discussions and consensus. The following information was recorded for each study: the first author name, year of publication, number of cases, sample source, micro- and macroproteinuria, and clinicopathological parameters. Two investigators reviewed all the articles that fit the inclusion and exclusion criteria. Heterogeneity of data was evaluated to determine whether or not the data of the various studies could be analyzed. Data for study characteristics and clinical response were summarized and represented in table format.

\section{Statistical analysis}

We used RevMan 5.2 (The Nordic Cochrane Centre, Copenhagen, Denmark) and the Stata 12.0 (Stata Corporation, College Station, TX, USA) for this analysis. Comparisons of dichotomous measures were determined by pooled estimates of odds ratios (ORs) as well as their $95 \%$ confidence intervals (CIs). Heterogeneity was determined by a chi-square test, with significance being set at $P<0.10$; the total variation among studies was estimated by $I^{2}$, with significance being set at $I^{2}>50 \%$. A $P$-value of $<0.05$ was considered to be statistically significant. We used a random-effect model to pool the OR when there was heterogeneity among studies; otherwise, a fixed-effect model was selected. Studies reported albuminuria or proteinuria in different units that could not easily be compared. We referred to the methods by Kunz et $\mathrm{al}^{13}$ and we chose to summarize the therapeutic effects of sulodexide on urinary protein excretion using the ratio of the average therapeutic effects in the intervention group relative to the control group. This is roughly comparable across different measurement units and can be directly applied in a clinical context. ${ }^{14}$

We first collected 64 articles from PubMed, MEDLINE, and the Web of Science, Scopus, and EMBASE. Finally, 13 full-text studies were retracted for more detailed assessment, after initial screening of the titles and abstracts for eligibility. Of these, three crossover trials without placebo group as control were excluded. ${ }^{15-17}$ Eventually, several publications were selected and met the inclusion criteria for this meta-analysis. ${ }^{11,12,18-22}$ The article search process and study selection are showed in Figure 1.

\section{Results}

\section{Study characteristics and quality}

Ten eligible studies published from 2005 to 2013 were finally selected for this study. A total of 2,770 patients, 


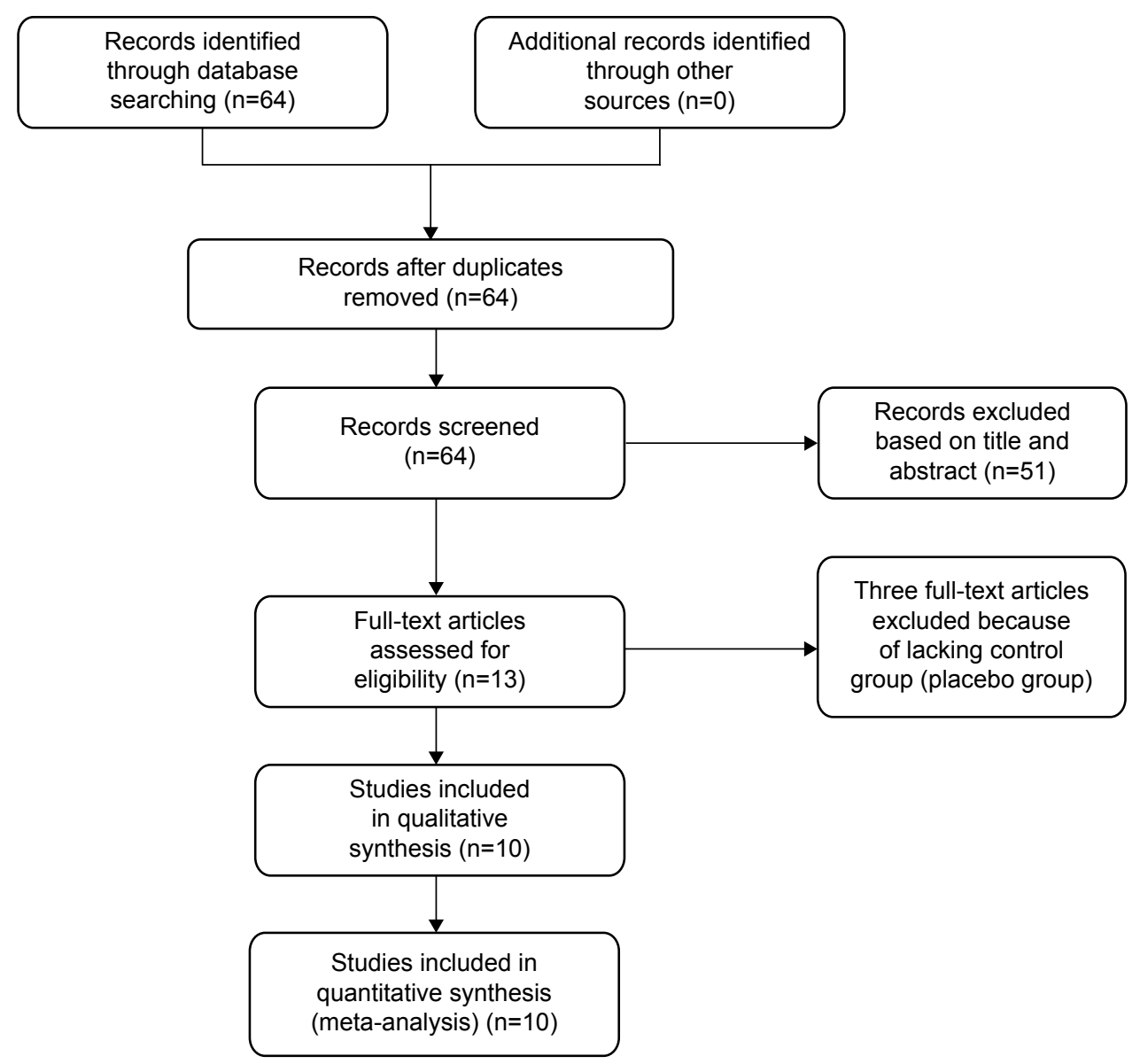

Figure I Flow chart of study selection.

including type 1 and type 2 diabetic patients from People's Republic of China, Australia/New Zealand, the Netherlands, Poland, Spain, United Kingdom, Canada, and the United States, were enrolled. Eventually, several publications were selected and met the inclusion criteria for this metaanalysis. ${ }^{11,12,18-22}$ Their basic characteristics and antiproteinuric effects are summarized in Table 1. The confounding factors in the placebo groups and sulodexide groups, such as patient number, age, baseline proteinuria parameters, and mean arterial pressure before treatment, are summarized in Table 2. It was shown that the confounding factors that influence urinary albumin excretion were well-balanced in the sulodexide and control groups. All these possible confounders were well-controlled in the cited works and did not affect the meta-analysis.

\section{Antiproteinuric effects of sulodexide (urine albumin excretion)}

Although the different primary diseases (type 1 or type 2 diabetes), stages of proteinuria (micro- or macro albuminuria), follow-up periods, and races may affect the effects of sulodexide on proteinuria, we combined all the data for an analysis due to limited information under each specific situation. We took the maximum maintenance phase of follow up (not including the washout phase) in each study if multiple follow-up periods were available and compared the mean ratios of urine albumin excretion rate (AER) between the sulodexide and placebo groups (baseline proteinuria levels before therapy vs those after therapy). Overall, sulodexide therapy was associated with a significant reduction in urinary protein excretion. The ratio of means comparing the means of patients between the sulodexide and placebo groups from eight studies was: 0.76 (95\% CI, 0.62-0.93, $z=2.63, P=0.009)$ (Figure 2). We conducted a random-effect meta-analysis, since $I^{2}=70 \%$. We removed one study at a time to analyze sensitivity and found the pooled ratio of means was not significantly changed, indicating the quality of the studies was acceptable.

Then, we compared the proportions of patients achieving the therapeutic success, defined as at least a $50 \%$ decrease in $\mathrm{AER}^{11}$ when treated with sulodexide. This criterion was similar to those used in the study by Heerspink et $\mathrm{al}^{21}$ which 


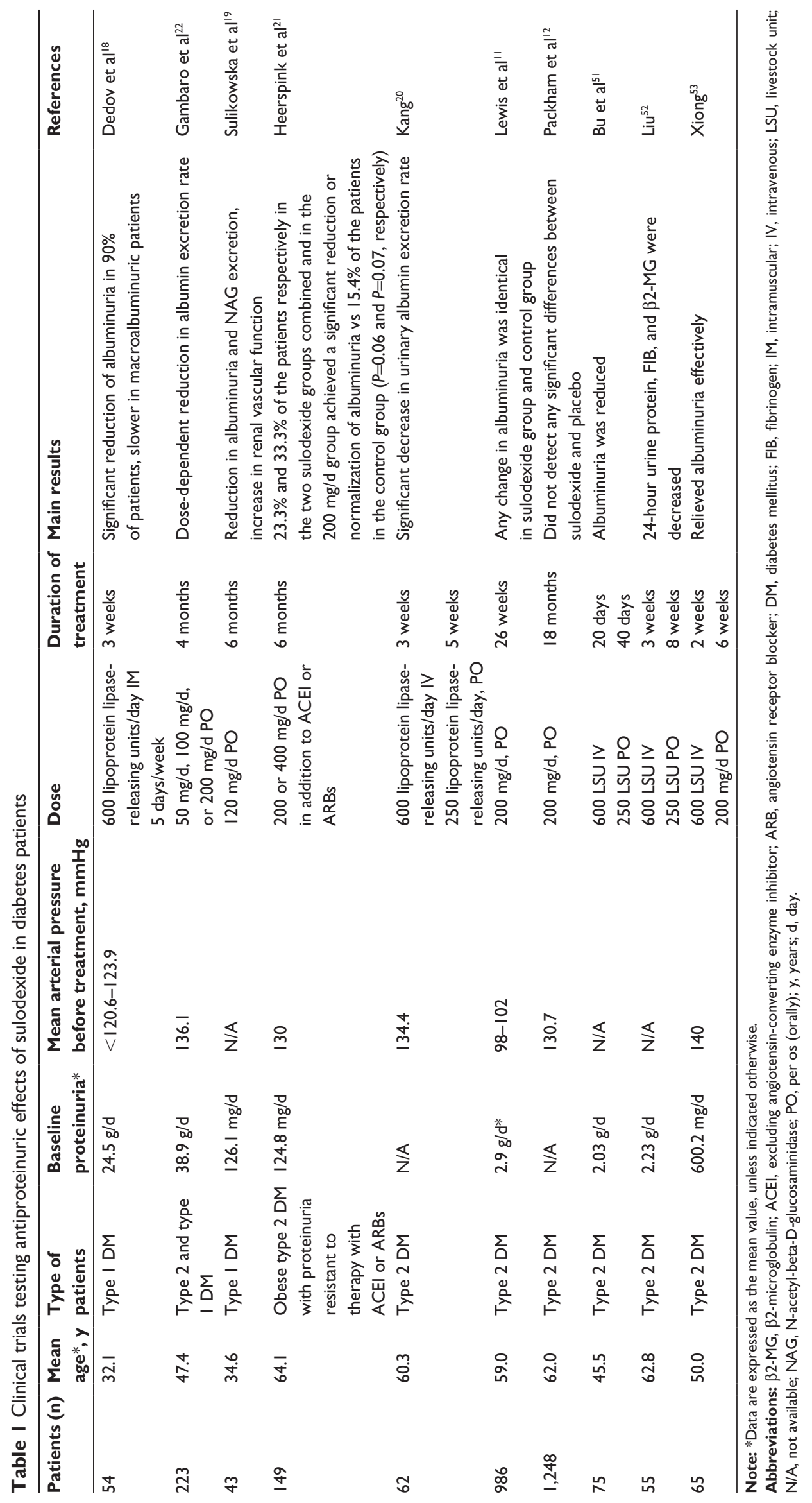




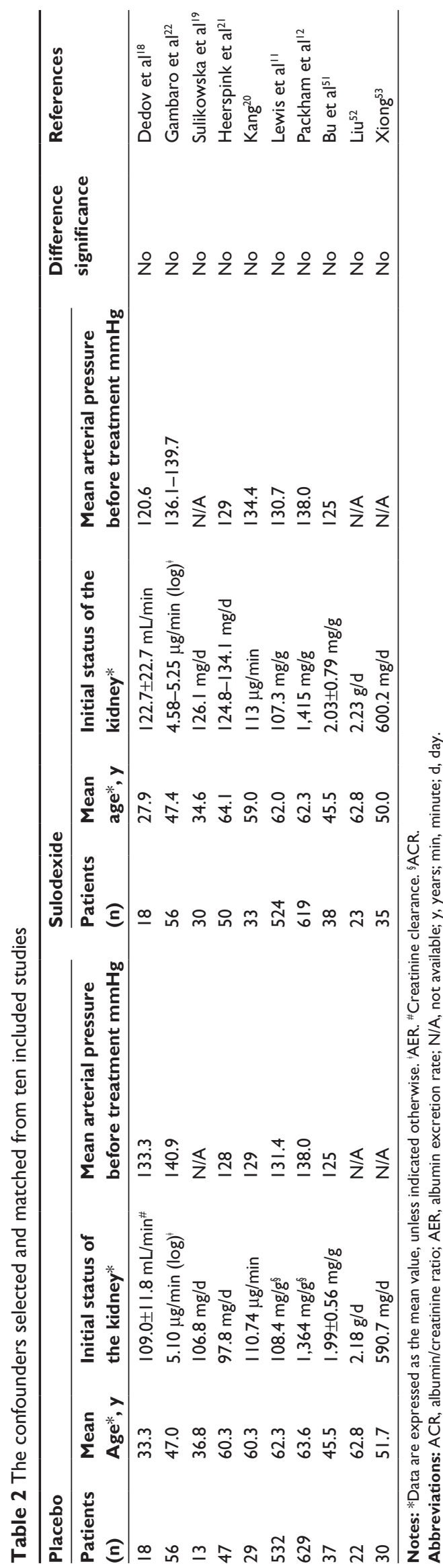

defined therapeutic success as a binary composite end point, as either 1) conversion to normoalbuminuria (albumin to creatinine ratio $[\mathrm{ACR}]<20 \mathrm{mg} / \mathrm{g}$ ) and a $25 \%$ reduction in ACR from the baseline level, or 2) a $50 \%$ reduction in ACR from baseline. Heerspink et al also showed positive correlation between 24-hour urine AER and the geometric mean of the three first-morning spot urine ACRs. ${ }^{21}$ Overall, in six of the qualifying studies, $220(19.5 \%)$ achieved at least a 50\% decrease in AER in the sulodexide group compared with only $165(13.0 \%)$ in the placebo. Notably, two studies ${ }^{18,23}$ had no subject in one cell, and we modified the data with zero according to previous publications. According to Wilson ${ }^{24}$ a usual way to deal with this problem is to add 0.5 to each of the four cells in the $2 \times 2$ table - this is known as Haldane's approximation. In meta-analysis, Haldane's approximation can also be applied, by either of two approaches: add 0.5 to only the trials with a zero cell or to all the trials in the meta-analysis. Little is known regarding which approach is better when used in combination with different definitions of the OR: the ordinary odds ratio, Peto's OR, or Mantel-Haenszel OR. In addition, Friedrich et $\mathrm{a}^{25}$ also concluded that to include all relevant data, regardless of effect measure chosen, reviewers should also include zero total event trials when calculating pooled estimates using OR and RR. We add " 1 " to two trials with zero (since the minimum input in the cell of RevMan 5.3 is " 1 "). Then we reanalyzed the data, and the modified data are shown in the "Results" section. Although high heterogeneity existed, the OR did not change significantly when two studies were removed from the meta-analysis. The OR comparing the proportion of patients with therapeutic success between the sulodexide and placebo groups from six qualifying papers was 3.28 ( $95 \%$ CI, $1.34-8.06, z=2.59$; $P=0.01$ ) (Figure 3).

\section{Changes in serum creatinine and creatinine clearance}

There were no significant differences in the change of serum creatinine and creatinine clearance between the two groups. The ratio of means, comparing the means of patients between the sulodexide and placebo groups was 1.03 (95\% CI, 0.89-1.19, $P=0.69$ ) (Figure 4).

No heterogeneity was observed in the analysis of the effects of sulodexide on AER (Figure 2) and serum creatinine (Figure 4), so the fixed-effect model was used. There was a heterogeneity found in the analysis of the effects of sulodexide on the achievement of therapeutic success (Figure 3), so the random effect model was used. 


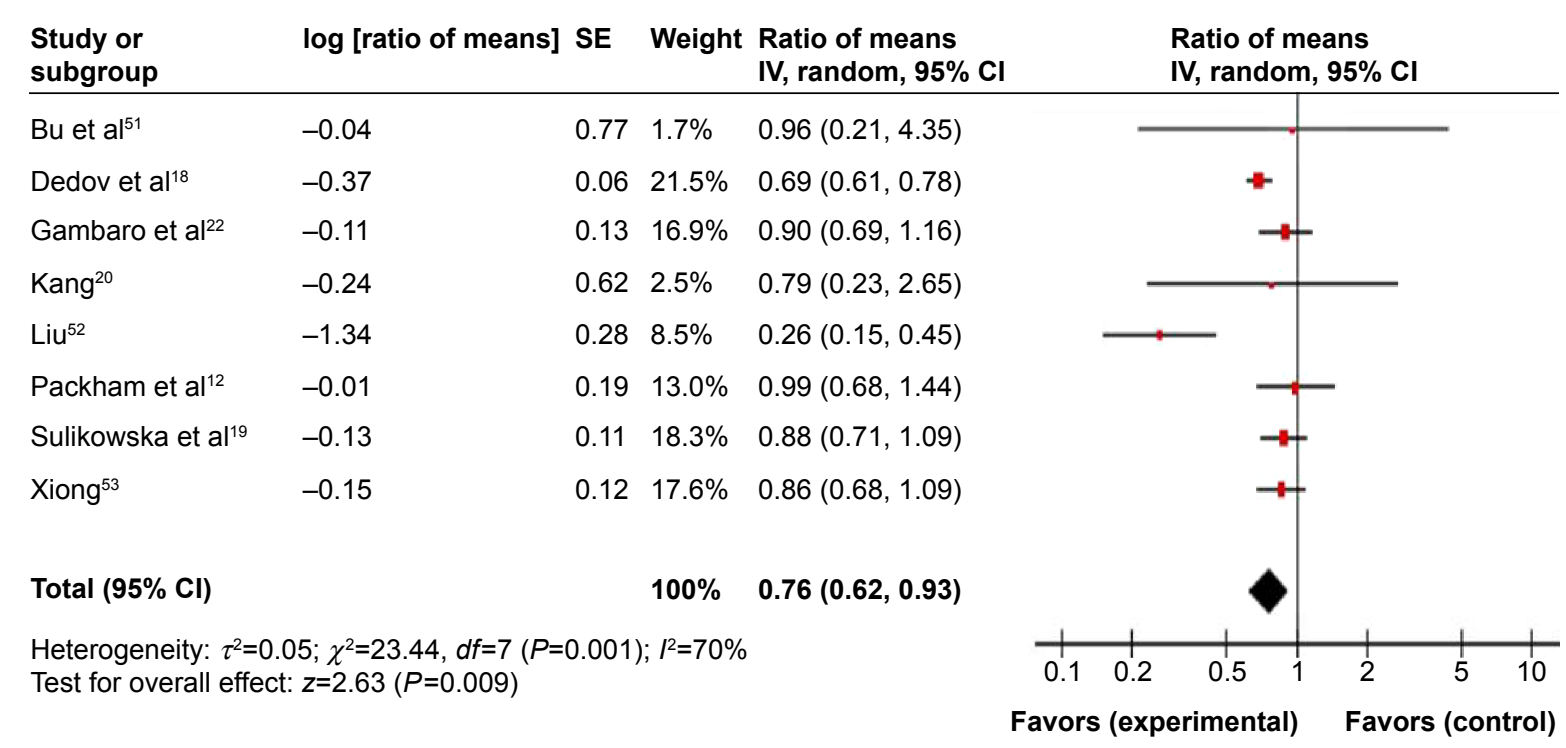

Figure 2 Antiproteinuric effects of sulodexide, as assessed by the reduction of AER from eight studies. Notes: $O R=0.76,95 \% \mathrm{Cl}, 0.62-0.93, P=0.009$.

Abbreviations: $\mathrm{AER}$, albumin excretion rate; $\mathrm{Cl}$, confidence interval; $\mathrm{OR}$, odds ratio; $\mathrm{SE}$, standard error of the mean; IV, inverse variance.

\section{Side effects}

Four trials briefly described the adverse events. ${ }^{11,12,18,21}$ The incidence of "likely related" side effects was similar in the sulodexide (ranging from $10.9 \%$ to $35.2 \%$ ) and placebo groups (ranging from $12.2 \%$ to $32.3 \%$ ). No serious adverse events were believed to be related to the study medication. The most common complaints were cardiovascular disorders; renal and urinary disorders; gastrointestinal and hepatobiliary disorders; infections and infestations; respiratory, thoracic, and mediastinal disorders; injury; poisoning, and procedural complications; metabolism and nutrition disorders; neoplasms (benign, malignant, and unspecified); musculoskeletal and connective tissue disorders; general disorders; administration-site conditions, eye disorders; nervous system disorders; vascular disorders; endocrine, reproductive, and breast disorders; blood and lymphatic system disorders; and ear and labyrinth disorders. ${ }^{11,12,18,21}$

\section{Publication bias and sensitivity analyses}

A sensitivity analysis was conducted to assess the result stability, using the method in which one study was removed at a time. The pooled ratio of means and ORs were not significantly changed, indicating the stability of our study. The funnel plots were largely symmetric (Figure 5), suggesting

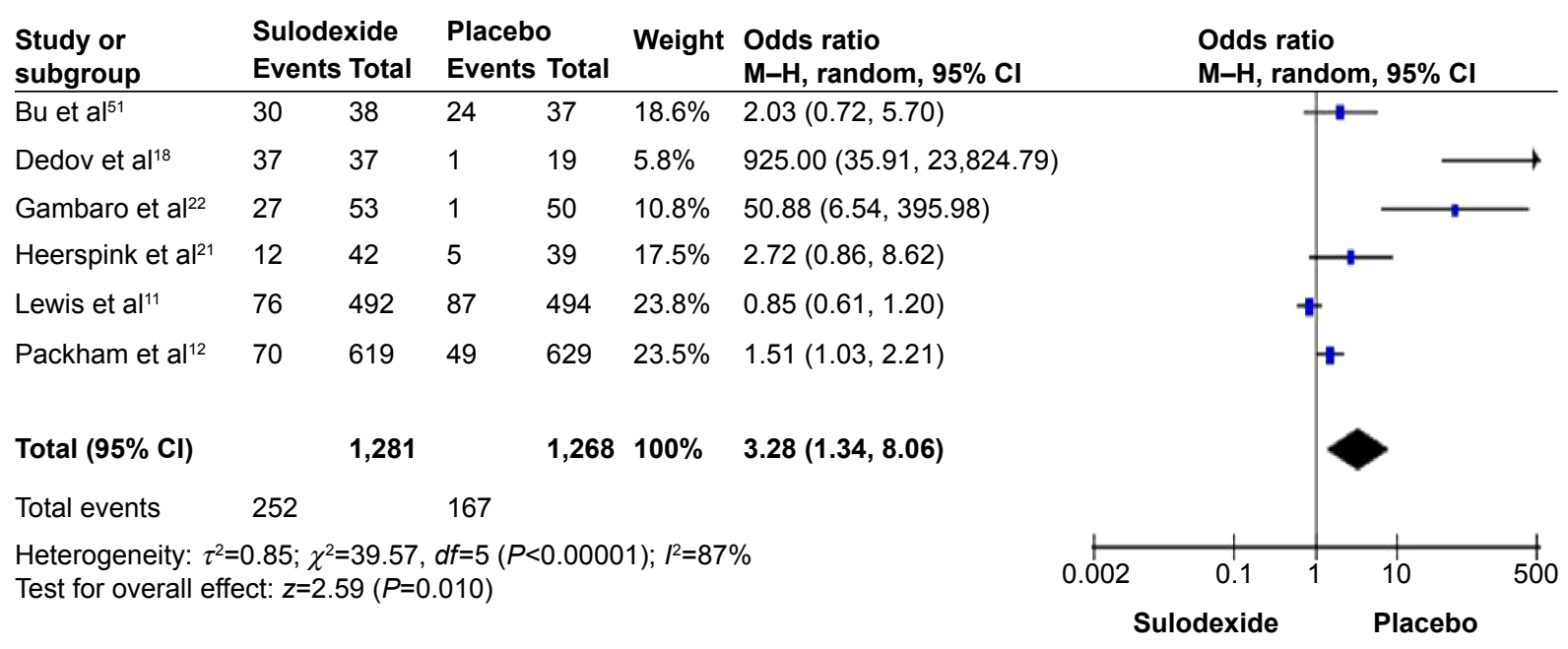

Figure 3 Antiproteinuric effects of sulodexide, as assessed by the proportion of patients to achieve the therapeutic effect from six studies. Notes: $O R=3.28,95 \% \mathrm{Cl}, \mathrm{I} .34-8.06, P=0.01$.

Abbreviations: $\mathrm{Cl}$, confidence interval; OR, odds ratio; $\mathrm{M}-\mathrm{H}$, Mantel-Haenszel test. 


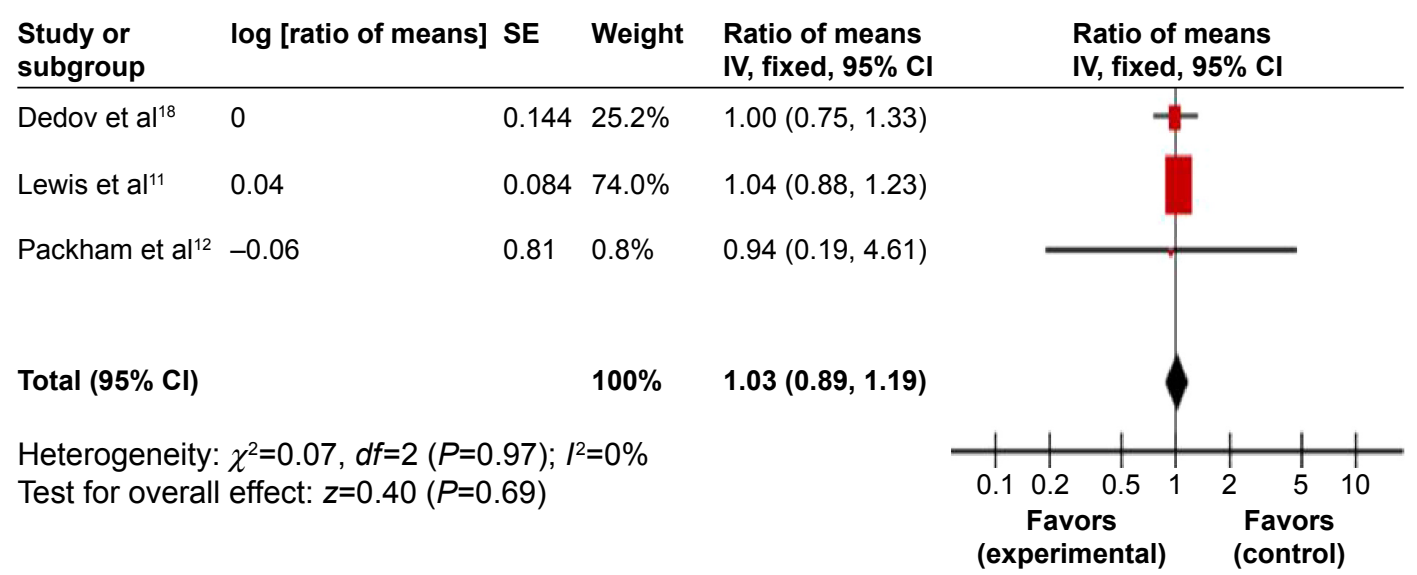

Figure 4 Changes in serum creatinine, from three studies.

Notes: Ratio of means $=1.03,95 \% \mathrm{Cl}, 0.89-1.19, P=0.69$.

Abbreviations: $\mathrm{Cl}$, confidence interval; $\mathrm{SE}$, standard error of the mean.

there were no publication biases in the meta-analysis of sulodexide and clinicopathological features.

\section{Discussion}

DN occurs in $20 \%$ to $40 \%$ of patients with DM and is the major cause of morbidity and mortality in patients with type 1 and type $2 \mathrm{DM}^{26}$ The earliest clinical evidence of nephropathy is an increase in microalbuminuria, defined as more than $30 \mathrm{mg} /$ day into the macroalbuminuria defined as more than $300 \mathrm{mg} /$ day. $^{27-29}$ Several clinical trials have indicated a slow improvement of kidney function using agents, such as ACEIs and ARBs in concert with diuretics and calcium channel blockers, to block the renin-angiotensin-aldosterone system (RAAS). ${ }^{29}$ As researchers have gained a clearer understanding of the pathophysiological mechanisms of DN, several new therapeutic agents have been subjected to clinical trials, including anti-TGF- $\beta$ monoclonal antibody, ${ }^{30}$ anticonnective tissue growth factor monoclonal antibody ${ }^{31}$.

As a component of the GBM, the heparin sulfate proteoglycans (GAGs) strongly influence the permeability of the glomerular filtration barrier by affecting its thickness and
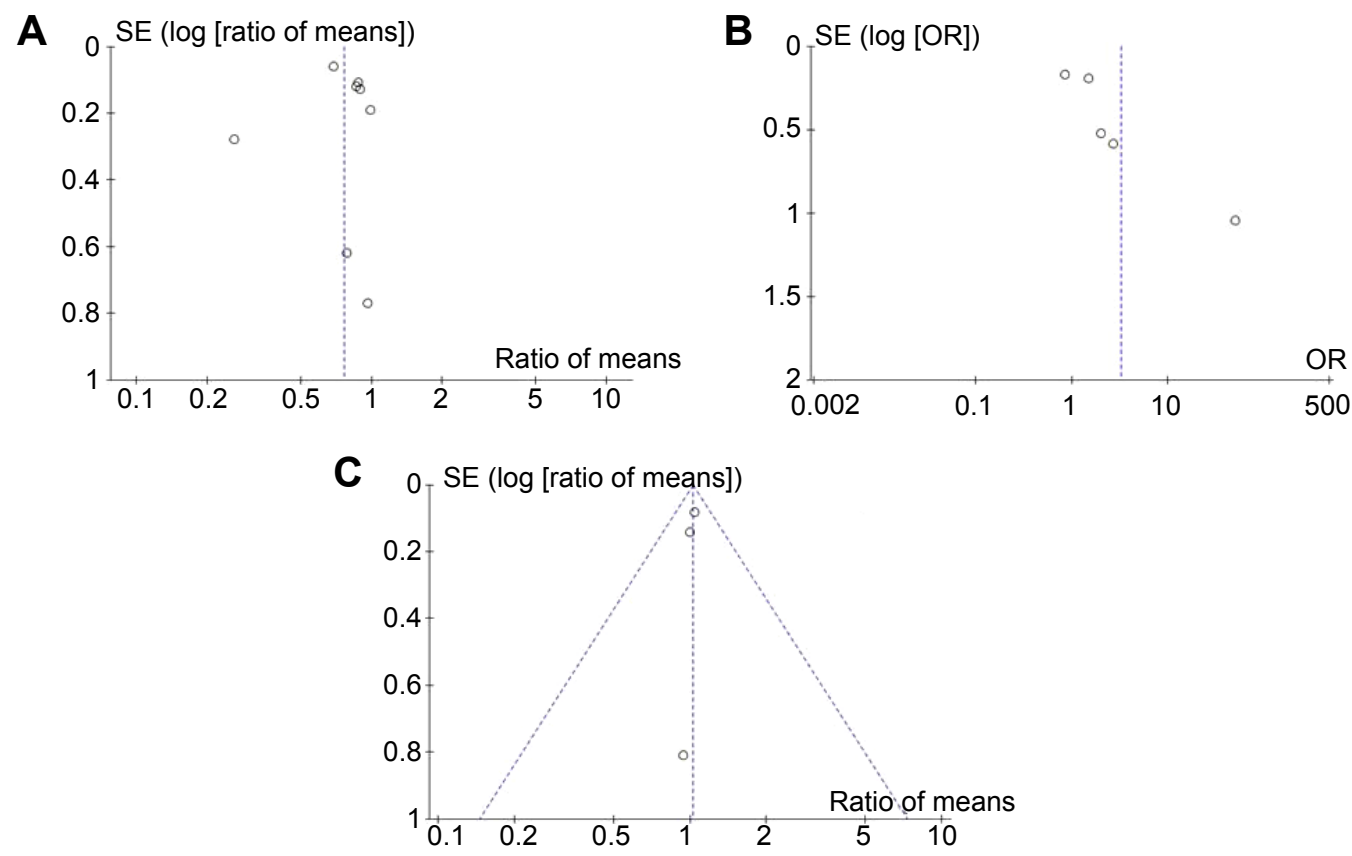

Figure $\mathbf{5}$ The funnel plots for sulodexide and clinicopathological features.

Notes: (A) Antiproteinuric effects of sulodexide, as assessed by reduction of AER. (B) Antiproteinuric effects of sulodexide, as assessed by the proportion of patients to achieve the therapeutic effect. (C) Changes in serum creatinine.

Abbreviations: $A E R$, albumin excretion rate; OR, odds ratio; SE, standard error of the mean. 
anionic charges. ${ }^{32,33}$ A decrease in the GAG composition of the GBM, particularly in heparin sulfate, is associated with diabetic kidney diseases. The loss of GBM integrity could worsen proteinuria and accelerate the progression of end-stage renal disease. ${ }^{34}$ Sulodexide is a GAG extract of the porcine lung and liver, and its major components are low-molecular-weight heparin and dermatan sulfate. ${ }^{35}$ Many preliminary data demonstrated that orally administrated sulodexide was able to reduce urine alumina excretion in diabetic patients. ${ }^{36-41}$ However, in two large randomized double-blinded placebo-controlled trials led by Lewis et al and Packham et al which involved around 1,000 subjects with type 2 DM with micro- and macroalbuminuria in each trial, sulodexide failed to reduce urine albumin excretion compared with placebo. ${ }^{11,12}$ Therefore, the use of sulodexide for diabetic therapy was considered as "another one bites the dust", to be abandoned. ${ }^{42}$

Gambaro $^{23}$ and Coccheri, ${ }^{43}$ who also led clinical trials of the effects of sulodexide on DN, disagreed with the conclusions of Lewis et al. They argued that discounting the efficacy of sulodexide in DN was premature. They interpreted the negative results obtained by Lewis et al differently: First, the drug used in the Collaborative Study Group trial by Lewis et al ${ }^{11}$ was only tested for heparin fraction activity without consideration for the dermatan sulfate, which constitutes one-fifth of the active ingredients of the drug. Second, treatment with maximal doses of concomitant drugs, such as ACEIs and ARBs, left little allowance for a superimposed effect of sulodexide. Third, patients in the Collaborative Study Group trials had more severe DN than did those in previous trials. In this meta-analysis, we showed that sulodexide therapy was associated with a significant reduction in urinary protein excretion (Figures 2 and 3) both in reduced AER and proportion of subjects achieving therapeutic success.

Sulodexide has a renoprotective effect through restoration of glomerular ionic permselectivity, but the exact mechanism is still unclear. Several mechanisms have been proposed, one of which is dependent on GBM permselectivity, ${ }^{44,45}$ where sulodexide reduces proteinuria and improves renal function via inhibition of PKC- $\beta$ III, ERK, FGF-2, and heparanase-1, preventing epithelial-mesenchymal transition. Another proposed mechanism is independent of GBM permselectivity, in which sulodexide improves endothelial dysfunction through reduction of vascular endothelial growth factor. ${ }^{46-48}$

In addition, a recent experimental animal model study has indicated that sulodexide may protect early but not late nephropathy (radiation and DN). ${ }^{49}$ Taken together, it is too early to say that sulodexide is ineffective in the treatment of diabetic nephropathy - the findings from both clinical trials and experimental models should be viewed as justification for continuing to develop this drug into clinical application.

\section{Disclosure}

The authors report no conflicts of interest in this work.

\section{References}

1. Achour A, Kacem M, Dibej K, Skhiri H, Bouraoui S, El May M. One year course of oral sulodexide in the management of diabetic nephropathy. J Nephrol. 2005;18(5):568-574.

2. Ravera M, Re M, Weiss U, Deferrari L, Deferrari G. Emerging therapeutic strategies in diabetic nephropathy. J Nephrology. 2007;20 Suppl 12: S23-S32.

3. Reidy K, Kang HM, Hostetter T, Susztak K. Molecular mechanisms of diabetic kidney disease. J Clin Invest. 2014:124(6):2333-2340.

4. Toth-Manikowski S, Atta MG. Diabetic kidney disease: pathophysiology and therapeutic targets. J Diabetes Res. 2015;2015:697010.

5. Valociková I. [Sulodexid and nephrotic syndrome in patients with diabetic nephropathy]. Vnitr Lek. 2011;57(5):507-510. Slovak.

6. Shestakova MV, Chugunova LA, Vorontsov AV, Dedov II. [The efficacy of Sulodexide - a low-molecular heparin - in the therapy of diabetic nephropathy.] Ter Arkh. 1997;69(6):34-37. Russian.

7. Lauver DA, Lucchesi BR. Sulodexide: a renewed interest in this glycosaminoglycan. Cardiovasc Drug Rev. 2006;24(3-4):214-226.

8. Reeves WB, Rawal BB, Abdel-Rahman EM, Awad AS. Therapeutic modalities in diabetic nephropathy: future approaches. Open J Nephrol. 2012;2(2):5-18.

9. Zalevskaia AG, Astamirova KhS, Karpova IA, Popova SG. [A trial of the use of the low-molecular heparin sulodexide in the therapy of diabetic nephropathy.] Ter Arkh. 1998;70(3):71-74. Russian.

10. Skrha J, Perusicová J, Kvasnicka J, Hilgertová J. The effect of glycosaminoglycan sulodexide on oxidative stress and fibrinolysis in diabetes mellitus. Sb Lek. 1998;99(2):103-109.

11. Lewis EJ, Lewis JB, Greene T, et al; Collaborative Study Group. Sulodexide for kidney protection in type 2 diabetes patients with microalbuminuria: a randomized controlled trial. Am J Kidney Dis. 2011;58(5):729-736.

12. Packham DK, Wolfe R, Reutens AT, et al; Collaborative Study Group. Sulodexide fails to demonstrate renoprotection in overt type 2 diabetic nephropathy. J Am Soc Nephrol. 2012;23(1):123-130.

13. Kunz R, Friedrich C, Wolbers M, Mann JF. Meta-analysis: effect of monotherapy and combination therapy with inhibitors of the renin angiotensin system on proteinuria in renal disease. Ann Intern Med. 2008; 148(1):30-48.

14. Friedrich JO, Adhikari N, Herridge MS, Beyene J. Meta-analysis: low-dose dopamine increases urine output but does not prevent renal dysfunction or death. Ann Intern Med. 2005;142(7):510-524.

15. Poplawska A, Szelachowska M, Topolska J, Wysocka-Solowie B, Kinalska I. Effect of glycosaminoglycans on urinary albumin excretion in insulin-dependent diabetic patients with micro- or macroalbuminuria. Diabetes Res Clin Pract. 1997;38(2):109-114.

16. Skrha J, Perusicová J, Pont'uch P, Oksa A. Glycosaminoglycan sulodexide decreases albuminuria in diabetic patients. Diabetes Res Clin Pract. 1997;38(1):25-31.

17. Blouza S, Dakhli S, Abid H, et al; DAVET (Diabetic Albuminuria Vessel Tunisia Study Investigators). Efficacy of low-dose oral sulodexide in the management of diabetic nephropathy. J Nephrol. 2010; 23(4):415-424.

18. Dedov I, Shestakova M, Vorontzov A, Palazzini E. A randomized, controlled study of sulodexide therapy for the treatment of diabetic nephropathy. Nephrol Dial Transplant. 1997;12(11):2295-2300. 
19. Sulikowska B, Olejniczak H, Muszyńska M, et al. Effect of sulodexide on albuminuria, NAG excretion and glomerular filtration response to dopamine in diabetic patients. Am J Nephrol. 2006;26(6):621-628.

20. Kang Z. Study on effect of Sulodexide in treatment of diabetic nephropathy stage III. Guide of China Medicine. 2013;11:25-28. Chinese.

21. Heerspink HL, Greene T, Lewis JB, et al; Collaborative Study Group. Effects of sulodexide in patients with type 2 diabetes and persistent albuminuria. Nephrol Dial Transplant. 2008;23(6):1946-1954.

22. Gambaro G, Kinalska I, Oksa A, et al. Oral sulodexide reduces albuminuria in microalbuminuric and macroalbuminuric type 1 and type 2 diabetic patients: the Di.N.A.S. randomized trial. J Am Soc Nephrol. 2002;13(6):1615-1625.

23. Gambaro G. Discounting the efficacy of sulodexide in diabetic nephropathy is premature. Am J Kidney Dis. 2012;60(1):169-170.

24. Wilson TW. Dealing with Paucity of Data in Meta-Analysis of Binary Outcomes [doctoral thesis]. Hong Kong: The Chinese University of Hong Hong; 2006. Available from: http://www.hkcochrane.cuhk.edu. hk/thesis_final.pdf. Accessed July 15, 2015.

25. Friedrich JO, Adhikari NK, Beyene J. Inclusion of zero total event trials in meta-analyses maintains analytic consistency and incorporates all available data. BMC Med Res Methodol. 2007;7:5.

26. Radbill B, Murphy B, LeRoith D. Rationale and strategies for early detection and management of diabetic kidney disease. Mayo Clin Proc. 2008;83(12):1373-1381.

27. Rossing P. Diabetic nephropathy: worldwide epidemic and effects of current treatment on natural history. Curr Diab Rep. 2006;6(6):479-483.

28. Sarafidis PA, Khosla N, Bakris GL. Antihypertensive therapy in the presence of proteinuria. Am J Kidney Dis. 2007;49(1):12-26.

29. Khosla N, Bakris G. Lessons learned from recent hypertension trials about kidney disease. Clin J Am Soc Nephrol. 2006;1(2):229-235.

30. Ziyadeh FN, Sharma K. Overview: combating diabetic nephropathy. J Am Soc Nephrol. 2003;14(5):1355-1357.

31. Adler SG, Schwartz S, Williams ME, et al. Phase 1 study of anti-CTGF monoclonal antibody in patients with diabetes and microalbuminuria Clin J Am Soc Nephrol. 2010;5(8):1420-1428.

32. Miner JH. Glomerular filtration: the charge debate charges ahead. Kidney Int. 2008;74(3):259-261

33. Gaddi AV, Cicero AF, Gambaro G. Nephroprotective action of glycosaminoglycans: why the pharmacological properties of sulodexide might be reconsidered. Int J Nephrol Renovasc Dis. 2010;3:99-105.

34. Parthasarathy N, Spiro RG. Effect of diabetes on the glycosaminoglycan component of the human glomerular basement membrane. Diabetes. 1982;31(8 Pt 1):738-741.

35. Tanios BY, Ziyadeh FN. Emerging therapies for diabetic nephropathy patients: beyond blockade of the renin-angiotensin system. Nephron Extra. 2012;2(1):278-282.

36. Shimomura H, Spiro RG. Studies on macromolecular components of human glomerular basement membrane and alterations in diabetes. Decreased levels of heparan sulfate proteoglycan and laminin. Diabetes. 1987;36(3):374-381.
37. Solini A, Vergnani L, Ricci F, Crepaldi G. Glycosaminoglycans delay the progression of nephropathy in NIDDM. Diabetes Care. 1997; 20(5):819-823.

38. Masola V, Zaza G, Gambaro G. Sulodexide and glycosaminoglycans in the progression of renal disease. Nephrol Dial Transplant. 2014; 29 Suppl 1:i74-i79.

39. Weiss R, Niecestro R, Raz I. The role of sulodexide in the treatment of diabetic nephropathy. Drugs. 2007;67(18):2681-2696.

40. Abaterusso C, Gambaro G. The role of glycosaminoglycans and sulodexide in the treatment of diabetic nephropathy. Treat Endocrinol. 2006;5(4):211-222.

41. Wijnhoven T, Lensen JF, Rops AL, et al. Anti-proteinuric effects of glycosaminoglycan-based drugs. Curr Opin Mol Ther. 2007;9(4): 364-377.

42. House AA, Weir MA. Sulodexide for diabetic nephropathy: another one bites the dust. Am J Kidney Dis. 2011;58(5):692-694.

43. Coccheri S. Game not over for sulodexide. Am J Kidney Dis. 2012; 59(3):467

44. Yung S, Chau MK, Zhang Q, Zhang CZ, Chan TM. Sulodexide decreases albuminuria and regulates matrix protein accumulation in C57BL/6 mice with streptozotocin-induced type I diabetic nephropathy. PLoS One. 2013;8(1):e54501.

45. Masola V, Onisto M, Zaza G, Lupo A, Gambaro G. A new mechanism of action of sulodexide in diabetic nephropathy: inhibits heparanase-1 and prevents FGF-2-induced renal epithelial-mesenchymal transition. J Transl Med. 2012;10:213.

46. Cha JJ, Kang YS, Hyun YY, et al. Sulodexide improves renal function through reduction of vascular endothelial growth factor in type 2 diabetic rats. Life Sci. 2013;92(23):1118-1124.

47. Kristová V, Lísková S, Sotníková R, Vojtko R, Kurtanský A. Sulodexide improves endothelial dysfunction in streptozotocin-induced diabetes in rats. Physiol Res. 2008;57(3):491-494.

48. Coccheri S, Mannello F. Development and use of sulodexide in vascular diseases: implications for treatment. Drug Des Devel Ther. 2014; 8:49-65.

49. Rossini M, Naito T, Yang H, et al. Sulodexide ameliorates early but not late kidney disease in models of radiation nephropathy and diabetic nephropathy. Nephrol Dial Transplant. 2010;25(6):1803-1810.

50. Lambers Heerspink HJ, Fowler MJ, Volgi J, et al; Collaborative Study Group. Rationale for and study design of the sulodexide trials in Type 2 diabetic, hypertensive patients with microalbuminuria or overt nephropathy. Diabet Med. 2007;24(11):1290-1295.

51. Bu H, Xu K, Zhang H. [The effect of sulodexide on the diabetic nephropathy.] Journal of Henan Medical College for Staff and Workers. 2012;24(2):146-147. Chinese.

52. Liu S. Therapeutic effects of sulodexide combined with benazapril on patients with diabetic kidney disease. Chin J Diffic and Compl Cas. 2011;10:21-22. Chinese.

53. Xiong Y. Treatment of sulodexide on albuminuria in early diabetic nephropathy. J Jianghan Univ (Nat Sci Ed). 2014;42:90-92. Chinese.

\section{Publish your work in this journal}

Drug Design, Development and Therapy is an international, peerreviewed open-access journal that spans the spectrum of drug design and development through to clinical applications. Clinical outcomes, patient safety, and programs for the development and effective, safe, and sustained use of medicines are a feature of the journal, which

\section{Dovepress}

has also been accepted for indexing on PubMed Central. The manuscript management system is completely online and includes a very quick and fair peer-review system, which is all easy to use. Visit http://www.dovepress.com/testimonials.php to read real quotes from published authors. 